\title{
Heridas por arma de fuego en pene y testículo
}

\author{
Gimeno Argente V, Bosquet Sanz M, Ramírez Backhaus M, Trassierra Villa M, Budía Alba A, \\ Jiménez Cruz JF.
}

Servicio de Urología. Hospital Universitario La Fe. Valencia.

Actas Urol Esp. 2006;30(9):965

$\mathrm{V}$

arón de 41 años de edad que acudió a urgencias por heridas de arma de fuego (escopeta de perdigones) en escroto, pene y cara interna del muslo derecho. A la exploración física presentó importante pérdida de sustancia cutánea en pene, diversas heridas de proyectiles en cara interna de muslo y hemiescroto derecho, con un gran edema y hematoma asociado. Como pruebas de imagen se solicitó radiografía simple de pelvis (Fig. 1), apreciando múltiples cuerpos metálicos en muslo y hemiescroto derecho. En la TC de pelvis (Fig. 2) se evidenció gran número de perdigones en testículo derecho con estallido del mismo, así como un importante hematoma intraescrotal y enfisema subcutáneo. Ante el alcance de las lesiones se procedió a exploración quirúrgica de urgencia, detectando un testículo fragmentado, desvitalizado e inviable para su reconstrucción, por lo que se decidió realizar orquiectomía derecha. De la misma forma, se repararon los defectos de continuidad cutáneos en región dorsal del pene, con resección de bordes anfractuosos de la herida y posterior sutura primaria de la misma. La evolución postoperatoria fue satisfactoria, aunque en las 4 semanas posteriores precisó de un injerto cutáneo debido a la necrosis de la piel del pene suturada.

Dr. V. Gimeno Argente

Servicio de Urología (secretaria)

Hospital Universitario La Fe

Avda. Campanar no 21

46009 Valencia

E-mail: vigiar71@hotmail.com

(Trabajo recibido el 21 de julio de 2006)

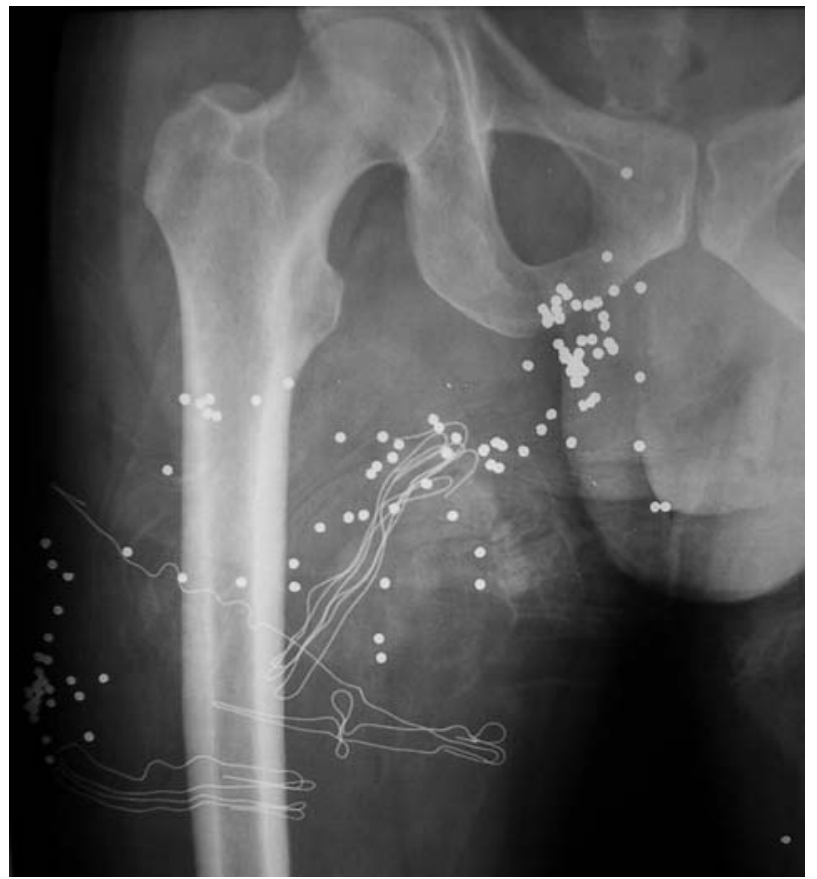

FIGURA 1

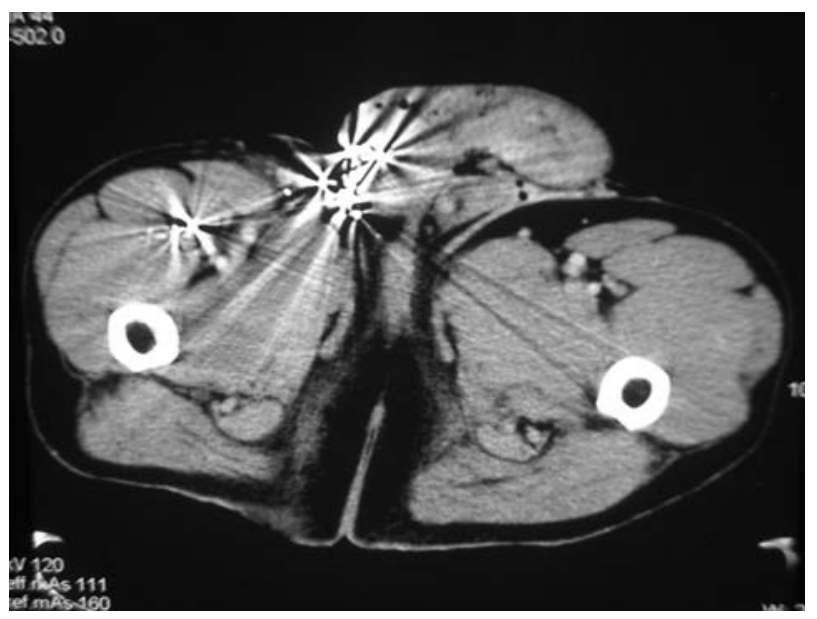

FIGURA 2 